\title{
Brucellosis: An Economically Important Infection
}

\section{Yasmin Bano ${ }^{1 *}$, and Sajad Ahmad Lone ${ }^{2}$}

${ }^{1}$ College of Life Sciences, Cancer Hospital and Research Institute Campus, Cancer Hills, Gwalior, Madhya Pradesh, India.

${ }^{2}$ Department of Environmental Sciences, Govt. Degree College Womens, Anantnag, Jammu \& Kashmir, India.

\begin{abstract}
Brucellosis is one of the world's major zoonosis, caused by bacteria of the genus Brucella. The world's most widespread zoonosis affects cattle, sheep, goats, pigs, and other animals, leading to abortion, infertility, and low milk yields. Humans acquire brucellosis from direct contact with livestock or from drinking unpasteurized milk. Brucella spp. are considered as the most common laboratory-acquired pathogens. Several serological tests have been widely used for diagnosis of Brucella such are Rose Bengal plate test (RBPT), Standard tube agglutination test (STAT), complement fixation test (CFT), enzyme linked immunosorbant assay (ELISA). Besides these, polymerase chain reaction (PCR) based identification and typing, fluorescence polarization assay (FPA) are also important diagnostic tools. The worldwide economic losses due to brucellosis are extensive. Although a number of successful vaccines are being used for immunization of animals still no satisfactory vaccine against human brucellosis is available. This review shows world literature and its impact to the history, epidemiology, virulence, diagnosis along with the control measures adopted in all over the world scenario including Indian.
\end{abstract}

Keywords: Brocellosis; Brucella; Zoonosis; Serological tests

\section{Introduction}

\section{Impact on health and economy}

Brucellosis is a highly infectious zoonotic disease and an economically important infection of humans and livestock with a worldwide distribution. It is a major veterinary and human public health problem in most parts of the world. The incidence of this disease is greatly decreased in the developed world due to effective vaccination based control programs, but remains an uncontrolled problem in regions of high endemicity such as the Mediterranean, Middle East, Africa, Latin America and parts of Asia including India [1-3]. Across the developing world, brucellosis is still a very common but often neglected disease. Brucellosis is of economic concern in many parts of the world as it results in reduced productivity, abortions, weak offspring's and major impediments for trade and export of livestock. It can also be transferred from animal to humans [4]. Brucellosis is a chronic disease with a risk of disabling consequences, but is rarely fatal in affected humans. Human brucellosis is a severe debilitating disease that requires prolonged treatment with the use of several antibiotics and also involves considerable medical expenses as well as loss of working hours. Brucellosis is almost invariably transmitted to man from infected domestic animals. However, it has been documented beyond doubt, the possibility of human to human transmission of Brucella infection [5-7] i.e. humans carry the disease, but person to person transmission of brucellosis is very rare, however transmission of the disease from human to human has been reported [8-10]. Mothers who are breast-feeding may transmit the infection to their infants and sexual transmission has also been reported $[10,11]$.

Besides a threat to human healthware brucellosis spread in livestock foci is also causing serious problems to the national economies. According to the International agreements on the veterinary regulation [12] if brucellosis is detected in at least one herd, the resettlement and sale of animals from the whole foci region should be prohibited. Such strict limitations lead to the significant brucellosis mediated economic losses.

Marston described the symptoms of brucellosis and also gave the name gastric remittent fever [13]. Brucellosis has many synonyms derived from the geographical area in which this disease is common, e.g. Mediterranean fever, Malta fever, Gibraltar fever, Cyprus fever. It was also known with the symptoms it is associated, undulant fever due its remittent character and typhomalarial fever due to its reassemble to malaria and typhoid fevers. That is why brucellosis is frequently misdiagnosed as malaria, typhoid, or venereal disease [14]. Brucellosis is also known as intermittent typhoid, bang's disease in cattle, contagious abortion, infection abortion, epizootic abortion.

This disease has been under reported from domestic animals from developing countries because of absence of national surveillance programs, diagnostic facilities and reliable data [15]. The principal symptom in all animal species is abortion or premature expulsion of the fetus. The main mode of transmission of this disease to humans is through consuming untreated milk products. Each year about a half million cases of brucellosis occurs in humans around the world [16]. There are three reports of humans infected with marine strains of Brucella; one reported in a research laboratory worker after occupational exposure [17] and other two were community-acquired infections $[18,19]$. Bovine brucellosis has been eradicated in Finland, Norway, Sweden, Denmark, Belgium, Switzerland, Germany, Austria, Hungary, the former Czechoslovakia, Rumania, and Bulgaria, as well as in other developed countries [20,21].

\section{Historical perspective}

Marston made the earliest recorded description of brucellosis in 1859 as he wrote of an illness, including his own, which differed from typhoid fever. Sir David Bruce isolated the organism from the spleen of a patient while investigating an outbreak of a fatal disease known as Mediterranean or Malta fever, affecting British soldiers stationed on the island of Malta [22]. He named the bacteria as Micrococcus

*Corresponding author: Yasmin Bano, College of Life Sciences, Cancer Hospita and Research Institute Campus, Cancer Hills, Gwalior, Madhya Pradesh, India, Tel: 0751233 6502; E-mail: yasmin_bano22@rediffmail.com

Received October 27, 2015; Accepted November 19, 2015; Published November 23, 2015

Citation: Yasmin B, Lone SA (2015) Brucellosis: An Economically Important Infection. J Med Microb Diagn 4: 208. doi:10.4172/2161-0703.1000208

Copyright: ( 2015 Bano Y, et al.. This is an open-access article distributed under the terms of the Creative Commons Attribution License, which permits unrestricted use, distribution, and reproduction in any medium, provided the original author and source are credited. 
melitensis due to coccoidal morphology. Hughes suggested the name undulant fever (wave like) because of characteristic fever, which rise and fall over weeks in untreated patients [23]. Write and Smith detected antibodies of $M$. melitensis through agglutination test in humans and explained the zoonotic potential of this disease [24] Zammit working with Mediterranean fever commission discovered the role of goats in brucellosis by isolation the organism from the milk and urine of the goats and concluded that goat was the reservoir and declared that consumption of the raw milk and cheese responsible for the human brucellosiss [25]. The report of isolation of a gram negative rod from cattle, its subsequent establishment of similarity between $M$. melitensis gave convincing evidence that both organisms could not be differentiated morphologically or by cultural and biochemical reactions. Both these bacteria were finally placed under one genus Brucella named in honour of Sir David Bruce.

\section{Classification and General Characteristics}

\section{Scientific classification}

Kingdom- Bacteria

Phylum-Proteobacteria

Class-Alphaproteobacteria

Order-Rhizobials

Family-Brucellaceae

Genus-Brucella

The traditional taxonomy is based on phenotypic characteristics, antigenic variations and prevalence of infection in different animal hosts. The common species of Brucella associated with different animal hosts are B. melitensis (goat and sheep), B. abortus (cattle), B. suis (pig, reindeer and hare), $B$. ovis (sheep), B. neotomae (desert wood rat), and B. canis (dog). B. pinnipediae (seal/ otter) and B. cetaceae (porpoise/ whale) have been reported from marine mammals [26,27]. Which of them human infections are common with B. melitensis [2,26]. B. abortus as a2 proteobacteria have phylogenetic relationships with Agrobacterium, Rickettsia, Rhizobium, Rhizobacter, Ochrobacterium $[28,29]$. Brucella has been subdivided into biovars based on different biochemical reactions and differentiated from other related species by conventional methods such as sensitivity or tolerance to aniline dyes, production of $\mathrm{H}_{2} \mathrm{~S}$ and $\mathrm{CO}_{2}$ requirements for growth. The taxonomy of Brucella species is still being resolved based on 16s-rRNA gene sequence. According to the new taxonomy used by NCBI the species B. melitensis includes 5 biovars namely, abortus, canis, neotomae, ovis, and suis (Table 1).

\section{Brucellosis in animals}

Brucellosis is a very important disease for bovines and buffaloes due to the reproductive problems it causes [30] and also the risk to public health. It is a barrier to the international trade of animals and animal products [31]. The main pathogen is B. abortus biovar 1 is universal in the presence and predominant among the seven that occurs in the world. The distribution of the different biovars varies geographically. Cattles can also become infected with B. suis, B. melitensis when they share pasture or facilities with infected pigs, goat and sheep. The infections in cattle caused by other species of Brucella are more sporadic and rarer in nature than the disease caused by $B$. abortus. In natural infections it is difficult to measure the incubation period (from time of infection to abortion or premature birth), as it is not possible to determine the moment of infection. Experiments have shown that the incubation period varies considerably and is inversely proportional to fetal development, i.e. the more advanced the pregnancy, the shorter the incubation period. If the female is infected orally during the breeding period, the incubation period can last up to 200 days, while if she is exposed six months after being bred, the incubation time is approximately two months. The period of "serologic incubation" (from the time of infection to the appearance of antibodies) lasts several

\begin{tabular}{|c|c|c|c|c|c|c|c|c|}
\hline \multicolumn{9}{|c|}{ Taxonomic characteristics of Brucella species } \\
\hline \multirow[b]{2}{*}{ Species } & \multirow[b]{2}{*}{ Bio- type } & \multirow{2}{*}{ Host reservoir } & \multicolumn{6}{|c|}{ Biochemical identification } \\
\hline & & & Fuchsin & Thionin & $\begin{array}{l}\text { Safranin } \\
\text {-inhibition }\end{array}$ & $\mathrm{H}_{2} \mathrm{~S}$ production & Urease & $\mathrm{CO}_{2}$ growth \\
\hline $\begin{array}{l}\text { B. mlitensis } \\
\text { (Bruce, 1887) }\end{array}$ & $1-3$ & Goats, sheep, camels & + & + & - & - & $\begin{array}{c}+ \\
\text { in } 24 \mathrm{hr} .\end{array}$ & - \\
\hline $\begin{array}{l}\text { B. abortus } \\
\text { (Bang, 1897) }\end{array}$ & $1-6,9$ & $\begin{array}{l}\text { Cows, camels, yaks, } \\
\text { buffalo }\end{array}$ & $\begin{array}{l}\stackrel{+}{\text { (except }} \\
\text { biotype 2) }\end{array}$ & $\begin{array}{c}- \\
\text { (biotype } 1 \\
2,4)\end{array}$ & - & $\begin{array}{l}+ \\
\text { (except biotype 5) }\end{array}$ & $\begin{array}{c}+ \\
\text { in } 24 \mathrm{hr} .\end{array}$ & + \\
\hline $\begin{array}{l}\text { B. suis } \\
\text { (Traum, 1914) }\end{array}$ & $1-5$ & $\begin{array}{l}\text { Pigs (biotypes } 1-3 \text { ), wild } \\
\text { hares (biotype 2), } \\
\text { Caribou (biotype 4), } \\
\text { reindeer (biotype 4), } \\
\text { wild rodents (biotype 5) }\end{array}$ & $\begin{array}{l}\text { - } \\
\text { (except } \\
\text { biotype 3) }\end{array}$ & + & + & $\stackrel{+}{\text { (biotype } 1)}$ & $\stackrel{+}{+}$ in 15 min. & - \\
\hline $\begin{array}{l}\text { B. canis } \\
\text { (Carmichael and } \\
\text { Bruner, 1968) } \\
\end{array}$ & -- & Canines & $+1-$ & + & - & - & $\begin{array}{c}+ \\
\text { in } 15 \mathrm{~min} .\end{array}$ & - \\
\hline $\begin{array}{l}\text { B. ovis } \\
\text { (Van drimmelen, } \\
1953)\end{array}$ & -- & Sheep & $\begin{array}{l}- \\
\text { for some } \\
\text { strains }\end{array}$ & & - & - & - & + \\
\hline $\begin{array}{l}\text { B. neotomae } \\
\text { (Stoenner and } \\
\text { Lackman, 1957) }\end{array}$ & -- & Rodents & - & & - & + & $\stackrel{+}{+}$ in 15 min. & - \\
\hline $\begin{array}{l}\text { B. pinnipediae and } \\
\text { B. cetaceae } \\
\text { (Ewalt et al., and } \\
\text { Ross et al., 1994) }\end{array}$ & -- & $\begin{array}{l}\text { Mink whales, dolphins, } \\
\text { porpoises (pinnipediae), } \\
\text { seals (cetaceae) }\end{array}$ & + & + & - & - & + & $\begin{array}{c}- \\
\text { for pinnipediae } \\
\text { and } \\
+ \\
\text { for cetaceae. }\end{array}$ \\
\hline
\end{tabular}

Table 1: Taxonomic characteristics of Brucella species. 
weeks to several months. The incubation period varies according to factors such as the virulence of the strain and dose of bacteria, the route of infection and the susceptibility of the animal. In short, incubation period varying from 5 days to 5 months and can progress in various forms: acute, chronic or asymptomatic [32].

In pregnant females, abortion occurs during the second half of the pregnancy, often with retention of the placenta and resultant metritis, which may cause permanent infertility. It is estimated that the infection causes a $20 \%$ to $25 \%$ loss in milk production as a result of interrupted lactation due to abortion and delayed conception. In bulls it may become localized in the testicles and adjacent genital glands. The bacteria enter the body of animals first multiply in the regional lymph nodes and the latter carried by the lymph and blood to different organs. In experimental infection, it is possible to isolate the agent from the bloodstream after two weeks of infection. Brucella organisms are most commonly found in the lymph nodes, uterus, udder, spleen, liver, and in bulls, the genital organs. Large quantities of erythritol, a carbohydrate that stimulates the multiplication of brucellae, have been found in cow placentas and this could explain the high susceptibility of bovine fetal tissues. The virulence of Brucella in cattle is mainly due to their ability to replicate intracellularly, preferentially utilize erythritol and inhibit the mature reproductive tract, which is high in this sugar [33]. Once an infected cow aborts or gives birth normally, the pathogen does not remain long in the uterus. The infection becomes chronic and the brucellae are harboured in the cow's lymph nodes and mammary glands [34].

Cows, especially when pregnant are most susceptible, although some researchers maintain that bulls are more resistant to the infection than females. Some less susceptible cows have generalized infections and suffer losses in the reproductive system and milk production for one or more years, but then gradually recover. In such animals, the agglutination titer become negative and both the reproductive system and milk production return to normal. However, most cows become infected and their agglutination titers remain positive for many years. Brucellosis spread rapidly from animal to animal, trading and movements of animals also help maintain active infection.

\section{Brucellosis in humans}

Brucellosis is a multi-systemic disease in human and may present with a broad spectrum of clinical manifestations and its complications can affect almost all organs and systems with varying incidence [3537]. It is fatal in $1 \%-5 \%$ of untreated cases $[38,39]$. The symptoms and clinical signs most commonly reported are fever, fatigue, malaise, sweats, headaches, myalgia, arthalgia and weight loss [40]. Some cases have been presented with only joint pain, low back ache, and involuntary movements of limbs, burning feet or ischemic heart attacks [41]. Human brucellosis usually manifests as an acute (less than two months) or sub-acute (2-12 months) febrile illness, which may persist and progress to a chronic stage referred as chronic fatigue syndrome [42]. Complications can be different depending on the specific site of infection [43] of which meningitis and meningoencephalitis is the most common complications seen in neurobrucellosis [44]. Neurobrucellosis has been reported as an exceptional cause of transient ischemic attacks [41]. In conclusion, it should be noted that brucellosis may affect essentially any organ and that reinforces the importance of brucellosis in differential diagnosis in endemic areas [45] (Figure 1).

\section{Mode of Transmission}

The disease is transmitted either through contaminated milk

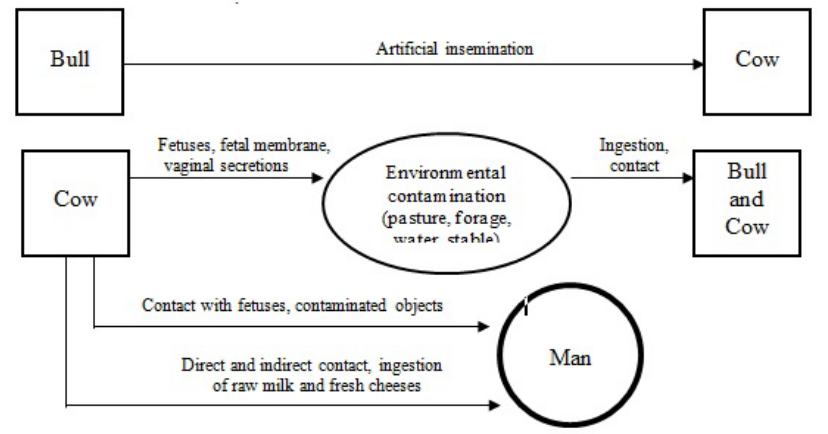

Figure 1: Brucellosis - Mode of transmission bovine brucellosis (Pedro and Boris, 2001).

products or through direct contact with infected animals. Fresh milk and dairy products prepared from unpasteurized milk such as soft cheeses, yoghurts and ice creams may contain high amounts of the bacteria and consumption of these is an important mode of transmission to humans [46]. It is also estimated that 10-100 organisms in aerosol form constitute an infectious dose. The bacterium may enter the body through digestive tract, the lungs or mucosal layer and spread through the blood and lymphatic system to any other organ where it may infect the tissue and cause localized. This is a common laboratory transmitted infection and reported to occur in clinical, research and production laboratories $[47,48]$. Bacterial load in animal muscle tissue is low, but consumption of undercooked traditional delicacies such as the liver has been implicated in human infection [49]. The main sources of infection for cattle are fetus and vaginal discharges. The most common route of transmission is the gastrointestinal tract following ingestion of contaminated pasture, feed, fodder, or water. Moreover, animals customarily lick afterbirth fetuses and newborn calves, which contain a large number of the bacteria. It has been shown experimentally that the organism may penetrate broken and even intact skin, but the mode of transmission of natural infection is unknown. Vaginal route and intrauterine route used in artificial insemination are very important in transmitting the infection.

\section{Global scenario}

The epidemiology of brucellosis is complex and Latin American countries, mainly Mexico and Peru reported a large number of cases. The same pattern holds true for Mediterranean countries like Iran, former Soviet Union and Mongolia. Seven republics of the former Soviet Union (Kyrgyzstan, Tajikistan, Kazakhstan, Azerbaijan, Turkmenistan, Armenia and Uzbekistan) are included in the 25 countries with the highest incidence of the disease worldwide, while another country of this region, Mongolia, is ranked the second. Syria has the highest annual incidence of human brucellosis worldwide [50]. Human brucellosis is found to have significant presence in rural/nomadic communities of these countries where people live in close association with animals. Worldwide, reported incidence of human brucellosis in endemic disease areas varies widely, from $<0.01$ to $>200$ per 100000 population [51] and about 500000 cases/year of human brucellosis are reported worldwide, but the estimates of the World Health Organization (WHO) suggest that, due to underreporting, the real incidence is $10-25$ times higher [52]. Despite the fact that incidence of human brucellosis is unknown for most countries including India and no data are available [53].

In Saudi Arabia, 7893 human cases of brucellosis were recorded in 1987 (74 per 100000 inhabitants). In Iran, 71051 cases (13 per 100000) were recorded in 1988 and it is estimated that 80000 cases have occurred 
each year since 1989. In turkey 5003 cases ( 9 per 100000) were recorded in 1990, an incident three times higher than the period 1986-1989 (3 per 100000).

In Europe, brucellosis is declining, according to data from the European Food Safety Authority (EFSA) the number of cases decreased from 735 in 2008 to 352 in 2011 [54]. The disease affects mostly the Mediterranean countries. From 2008 to 2011 Greece, Italy, Portugal and Spain accounted for $50-80 \%$ of all the European reported cases, respectively, with $B$. melitensis and $B$. abortus being the predominant causative agents [54].

The large meat producing countries such as France, Great Britain, Australia, New Zealand, Canada and United States are free of bovine brucellosis. The three important cattle raising countries, Argentina, Brazil and Mexico, still have limited control programs. A countryby-country analysis is found in a monograph on bovine brucellosis [34]. In the rest of the world, rates of infection vary greatly from one country to another and between regions within a country. Official estimates put annual losses from bovine brucellosis in Latin America at approximately US\$ 600 million [55]. A trend in the epidemiology of human brucellosis in Germany was investigated by analyzing national surveillance data (1962-2005) complemented by a questionnaire- based survey (1995-2000). The incidence decreased from 1962 to the 1980s' even though a persistent number of cases have been reported among Turkish immigrants $(0.3 / 10000$ Turks vs. $0.01 / 100000$ in the German population [56].

\section{Indian scenario}

India has a huge resource of livestock and dairy farming plays a substantial role in the country's rural economy [57]. The country restrains the largest buffalo population in the world (105.34 million $57.3 \%$ ) followed by the 2 nd largest cattle population (199.08 million - 14.7\%) [58] and highest milk production in the world, i.e. 121.8 million tonnes with per capita availability of $281 \mathrm{~g} /$ day [59]. Brucellosis is a highly contagious disease of dairy animals and humans in many parts of the world, including India causing significant morbidity and enormous economic losses $[60,61]$. The disease causes abortions in the last trimester of pregnancy, premature births followed by retention of placenta, metritis, decreased milk production and lameness as a common sequel to infection in dairy animals [62].

The occurrence of brucellosis in India was first established early in the previous century and since then has been reported from almost all states $[63,64]$. Many publications indicate that brucellosis is a fairly common disease in India and present in different species of mammalian farm animals including cattle, goats, buffalo, yaks, camel, horses and pigs [65-67]. A national survey in bovines a decade back indicated $5 \%$ of cattle and $3 \%$ of buffaloes of the country were infected with brucellosis [64]. The occurrence of the disease is usually high in organized farms (50\%) compared to the marginal herds $(10 \%)$ and this primarily associated with intensive farming practices in large organized animal farms $[53,68]$ reported $8.5 \%$ seroprevalence of brucellosis among the dairy persons with the isolation of Brucella strain from seven cases of human brucellosis. As many as $4.2 \%$ aborted women were seropositive for disease [69].

In Gujarat, 8.5\% [70] and in Hariyana, 34\% human brucellosis cases were reported among veterinarians, attendants and compounders who are in contact with animals [71]. In a study conducted by Hemashettar and Patil $24(8.2 \%)$ veterinary workers showed Brucella specific antibodies in significant titers [72]. A study by Mantur and coworkers in Bijapur reported 93 children among 5726 children as seropositive by SAT (>1:160) and confirmed it by the isolation of B. melitensis in 43 pediatric patients [73]. Handa and coworkers identified four cases with acute brucellosis in a group of 121 patients with FUO (Fever of Unknown Origin) [74].

\section{Genome}

The genome contains 2 circular chromosomes except B.suis biovar 3 , which has a single chromosome. The size of the first chromosome of $B$. abortus is 2,124,241 nucleotides long and codes for 2200 genes. The second chromosome is 1,162,204 nucleotides long and codes for 1156 genes. The genome has a GC content of $57 \%$, and $81 \%$ of the genome is coding region [75]. This pathogen is different from other bacterial species as it does not contain any plasmid or genomic islands that related to pathogenicity within its genome. In addition to lacking these two features, the genome also lacks many other genes that code for common virulence factors, including "capsules, fimbriae, exotoxins, cytolysins, resistance forms, antigenic variation, plasmids, or lysogenic phages" [76]. The genes that do encode for virulence in B. abortus are being examined, but they are not well understood to say for sure the mode of the virulence of this intracellular pathogen [26].

\section{Virulence and Pathogenicity}

There are many factors which responsible for human brucellosis. The S-LPS is a major determinant of virulence and dominants the antibody response. The elimination depends on activated macrophages and hence requires the development of Th1 type cell mediated immunity. Brucella LPS is a relatively poor inducer of gamma interferon and tumor necrosis factor $\alpha$, both of with are essential for the elimination of the organism [77]. The other important virulence factors include, production of inhibitory phagolysosome fusion such as adenine and guanine monophosphate levels [78]; outer membrane protein 25 which has been identified as the down regulator of TNF $\alpha$ [79] especially in the early stage of infection. Recently ureas enzyme has been identified as an important determinant of virulence as the areas enzyme protects bacteria in their passage through the stomach by oral route, which is the major way of infection in human brucellosis. Brucella is also considered as Class III pathogen and listed as a potential bio-threat agent that can be used in bioterrorism.

\section{Laboratory Diagnosis}

The varied symptoms which brucellosis presents make it troublesome for clinical diagnosis. The conventional diagnosis is microbiological confirmation by means of isolation of bacteria from the blood or from other body fluids. The isolation rate of Brucella is poor due to its slow growth rate, quantity of circulating viable bacteria, culture medium, blood culture techniques employed as well as presence of antibiotics that inhibits growth [80]. The demonstration of antibodies generated against Brucella by serological tests remains a viable alternative to culture and several serological tests like Standard Tube Agglutination Test (SAT) and Rose Bengal Plate Agglutination Test (RBPT) are the most popular serological tests used in the field for the diagnosis of brucellosis. Several workers have reported development of antibody detection systems based on ELISA.

Blood culture provides definite proof of brucellosis [81], but may not provide a positive result for all patients even under ideal conditions. Brucella is a slow growing organism and cultures are rarely positive and should be kept at least 45 days before the culture can be concluded negative. Many serological tests have been used for the diagnosis of brucellosis. The most commonly used tests are serum agglutination test 
(SAT), the coombs anti brucella test, rose bengal plate agglutination test (RBPT, based on agglutination of colored particulate antigen (killed Brucella organisms) by the antibodies present in the patient's serum), complement fixation test (CFT), indirect heamolysis test (IHLT). Since the development of the first agglutination test of brucellosis by Wright and Smith in 1897, veterinary laboratory workers have been developing tests to improve diagnostic performance and accuracy. Among the various tests developed are rapid agglutination tests for the detection of antibodies to brucellosis in cattle sera, such as the Rose Bengal Test [82], the Card Test [83], and the Buffered Antigen Plate Agglutination Test (BPAT) [84]. These tests use acidified antigens and were developed to improve accuracy. The purpose of the acidified antigens was to reduce agglutination by $\mathrm{IgM}$, thus reducing nonspecific false-positive reactions. Although rapid, these tests were largely laboratory based and subjective in the interpretation of results. With the exception of the BPAT, they did not significantly improve test accuracy [85]. The SAT detects IgG less efficiently, especially IgG1, resulting in low assay specificity [86-88]. Therefore, the SAT is generally not used as a single test, but rather in combination with other tests.

In 1897, Wright and Smith published the first description of a test for the serological diagnosis of brucellosis in man. After that, different diagnostic tests are developed and there is a need to improve them. Dotenzyme linked immunosorbent assay (dot-ELISA) for the detection of Brucella antibodies in human sera with autoclaved extract of $B$. abortus $S 99$ was developed and results were compared with those of STAT, RBPT and CFT. The dot-ELISA was found to be a more sensitive and also economical and rapid test for screening of human brucellosis under field conditions [89,90] evaluated a dot-ELISA (d-ELISA) test with the serum agglutination test (SAT), micro-complement fixation test (CFT) and a plate-ELISA (p-ELISA) for field use in screening herds of goats against brucellosis and found that d-ELISA was more suitable and rapid test for screening large numbers of goats in the field. YasminB and Selvam DT [91] found that d-ELISA formate had a high correlation, sensitivity and specificity in comparison with RBPT and plate ELISA. According to Shome et al., [92] the lateral flow assay (LFA) is a cost-effective and rapid technology that provides accurate detection of antibodies to B. abortus in bovine serum samples.

Brucella antibodies in bovine sera and milk was also detected using the dot-immunobinding assay (DIA), the serum agglutination test (SAT), the Rose Bengal plate test (RBPT) and the milk ring test (MRT). In DIA, B. abortus $S 99$ antigen prepared by heat treatment was used [93].The efficiency of a single antigen as well as a combination of two antigens in the complement fixation (CF) test was determined in detecting cattle and sheep infected or vaccinated. Comparative analysis of the CF results showed that the combined S99/RB51 antigen used in the CF test increases the specificity and sensitivity and could be used in animal brucellosis surveillance [94].

The humoral immunoresponse to $\mathrm{S}$ brucellae is dominated by antibodies to the PS (polysaccharide) section of the Brucella S-LPS (smooth lipopolysaccharide) and it shows a typical IgM/IgG (and IgA) shift. S-LPS or PS tests proposed for the diagnosis of human brucellosis, recently include the lateral flow immunochromatography assay (LFiC) for IgM and IgG assessment, a fluorescence polarization assay, a variety of indirect ELISA, and the immunocapture Brucellacapt test [95]. In addition, a competitive ELISA (cELISA) has been proposed [96]. In acute cases (i.e., short evolution) IgM is present in the serum; then this immunoglobulin returns progressively to background levels, so that $\operatorname{IgG}$ (and $\operatorname{IgA}$ ) are dominant in the sera of long evolution (i.e. chronic) patients before treatment.

\section{Treatment, control and prevention}

Uncomplicated acute brucellosis almost invariable responds well to appropriate antibiotic treatment $[97,98]$. Patients with complications, additional treatment, including in some cases surgical intervention will be necessary. To prevent disease progression and the development of complications, treatment should start as early as possible also in patients showing signs of spontaneous improvement. In all cases it is important that the patient finishes the full course of medication because the risk of incomplete recovery and relapse is otherwise increased considerably [99]. Either taking the combination of doxycycline and rifampicin (for 6 weeks), or the combination of doxycycline $(100 \mathrm{mg}$ twice/day orally for 6 weeks) with streptomycin ( $1 \mathrm{~g} /$ day for 2-3 weeks) is the standard treatment for brucellosis [100]. The effectiveness of the combination of streptomycin with a tetracycline has been acknowledged since the early days of antibiotic use [101], and the addition of rifampicin in treatment regimens for brucellosis also has a history of more than 30 years [102]. Treatment of complications such as spondylitis and osteomyelitis, neurobrucellosis and brucella endocarditis may require prolonged therapy for at least 8 weeks. Other combinations such as co-trimoxazole plus doxycycline and co-trimoxazole plus rifampin have been proposed, but still need further examination [103-106]. The optimal therapy for brucellosis during pregnancy has not been established [107].

The prevention of brucellosis is mainly by control of infection in domestic livestock by mass vaccination. The use B. abortus strain S19 in cattle and B. melitensis strain Rev-1 in goat and sheep has drastically reduced its incidence in many endemic areas. Vaccination of livestock is relatively cheap and will increase the value and productivity of their animals. It is not only important to improve the health of their animals but also is an important step to reduce the risk of severe illness and disability for themselves and their family members and also reduce the transmission to the human population. India already has developed a plan for the control of bovine brucellosis 3 but the non-availability of a human vaccine makes it necessary for the animal handlers, doctors and health care workers take protective measures. The avoidance of unpasteurised dairy products will prevent infection in the general population.

\section{References}

1. Lopez M (1989) Brucellosis in Latin America. In: young EJ, Corbel MJ (Ed), Brucellosis: Clinical and Laboratory Aspects: CRC press, Boca Raton, Florida 151-161.

2. Corbel MJ (1997) Brucellosis: an overview. Emerging Infectious Diseases 3 : 213-21.

3. Refai M (2002) Incidence and control of brucellosis in the Near East region. Veterinary Microbiology 90: 81-110.

4. Christopher W (2004) "Brucellosis in human". Department of Pathobiological Science, School of veterinary medicine, University of Wisconsin, Madison.

5. Naparstek E, Block CS, Slavin S (1982) Transmission of brucellosis by bone marrow transplantation. Lancet 1: 574-575.

6. Lubani MM, Dudin KI, Sharda DC, AbuSinna NM, Al-Shab T, et al. (1988) Neonatal brucellosis' European Journal of Pediatrics 147: 520-522.

7. Tikare NV, Mantur BG, Bidari LH (2008) Brucellar meningitis in an infantevidence for human breast milk transmission. Journal of Tropical Pediatrics 54: $272-274$

8. . Mantur BG, Mangalgi SS, Mulimani M (1996) Brucella melitensis-- a sexually transmissible agent? Lancet 347: 1763

9. Palanduz A, Palanduz S, Gruel K, Gruel N (2000) Brucellosis in a mother and her young infant: probable transmission of breast milk. International Journal of Infectious Diseases 4: 55-56.

10. Carrera Al, Lopez RMJ, Sapina AM, Lopez LA, Sacristan AR (2006) Probable 
transmission of brucellosis by breast milk. Journal of Tropical Pediatrics 52: 380-381.

11. Kato Y, Masuda G, Itoda I, Imamura A, Ajisawa A, et al. (2007) Brucellosis in a returned traveler and his wife: probable person-to-person transmission of Brucella melitensis. Journal of Travel Medicine 14: 343-345.

12. Office International des Épizooties (2000) "Manual of Standards for Diagnostic Tests and Vaccines," Office International des Épizooties, Paris.

13. Marston JA (1861) Report on fever (Malta). Great Britain Army Medical Department representative 3: 486 .

14. McDermott JJ, Arimib SM (2002) Brucellosis in sub-Saharan Africa: epidemiology, control and impact. Veterinary Microbiology 90: 111-134.

15. Cooper CW (1992) Risk factor in transmission of brucellosis from animal to humans in Saudi Arabia. Transactions of the Royal Society of Tropical Medicine and Hygiene 86: 206-209.

16. World Health Organization (1975) Fifth report on the World Health Situation. Geneva, 1969 -1972

17. Brew SD, Perrett LL, Stack JA, MacMillan AP, Staunton, NJ (1999) Human exposure to Brucella recovered from a sea mammal. Veterinary Record 144: 483

18. Sohn AH, Probert WS, Glaser CA, Gupta N, Bollen AW, et al. (2003) Human neurobrocellosis with intracerebral granuloma caused by a marine mammal Brucella sp. Emerging Infectious diseases 9: 485- 488.

19. McDonald WL, Jamaludin R, Mackereth G, Hansen M, Humphrey S, et al. (2006) Characterization of Brucella sp. Strain as a marine-mammal type despite isolation from a patient with spinal osteomyelitis in New Zealand. Journal of Clinical Microbiology 44: 4363- 4370.

20. Timm BM (1982) Brucellosis. Distribution in man, domestic and wild animals. Springer, Berlin.

21. Kasyanov AN, Aslanyan RG (1982) Epizootiology and clinical appearance of animal brucellosis. In: Lesenko A, ed zoonoses control Moscow, VII Centre projects.

22. Bruce Sir David (1887) Note On the Discovery of a Microorganism in Malta Fever, The Practioner 59: 161-170.

23. Hughes ML (1897) Mediterranean, Malta or Undulant Fever. Macmillan London, $1-10,28,80,85,148,156,166$.

24. Wright AE, Smith $F$ (1897) On the application of the serum test to the differential diagnosis of typhoid and Malta fever. Lancet 1: 656-9.

25. Zammit T (1905) Report of the commission on Mediterranean fever, part III. Harrison and Sons London $\mathrm{p} 83$.

26. Moreno E, Cloeckaert A, Moriyon I (2002) Brucella evolution and taxonomy. Veterinary Microbiology 90: 209-277.

27. Bricker BJ, Ewalt DR, Macmillan AP, Foster G, Brew S (2000) Molecular characterization of Brucella strains isolated from marine mammals. Journal of Clinical Microbiology 38: 1258-1262.

28. Moreno E, Stackebrandt, Dorsch M, Wolters J, et al. (1990) Brucella abortus 16s rRNA and lipid A reveal a phylogenetic relationship with members of the alpha-2 subdivision of the class proteobacteria. Journal of Bacteriology 35 : 292-295.

29. Moreno E, Moriyón I (2002) Brucella melitensis: A nasty bug with hidden credentials for virulence. Proceedings of the National Academy of Sciences 99: 1-3.

30. Nasir AA, Parveen Z, Shah A, Rashid M (2004) Seroprevalence of brucellosis in animals at government and private livestock farms in Punjab. Pakistan Veterinary Journal 24: 144-146.

31. Office International des Épizooties (2009) World Organization For Animal Health. Bovine brucellosis. Article 2.4.3. In: Terrestrial Manual 2009. V.2, part 2 , section 4 , chapter 2.4 .3

32. CDC (2008) "Public Health Consequences of a False-Positive Laboratory Test Result for Brucella-Florida, Georgia, and Michigan, 2005," Morbidity and Mortality Weekly Report (MMWR) 57: 603-605

33. Nicoletti P (1980) The epidemiology of bovine brucellosis. Advances in veterinary science and comparative medicine 24: 69-98.
34. Garcia-Carrillo C, Lucero NE (1993) Brucellosis bovina: Hemisferio Sur. Buenos Aires.

35. Andres MA, Burzako S, Montero GV, Franco VR (2003) Brucella endocarditis: two cases with medical treatment and successful outcome. Medicina Clínica (Barcelona) 120: 477.

36. Cesur S, Ciftci A, Sozen TH, Tekeli E (2003) A case of epididymo-orchitis and paravertebral abscess due to brucellosis. Journal of Infection 46: 251-253

37. Gur A, Geyik MF, Dikici B, Nas K, Cevik R, et al. (2003) Complications of brucellosis in different age groups: a study of 283 cases in southeastern Anatolia of Turkey. Yonsei Medical Journal 44: 33-44.

38. Dalrymple-Champneys W (1960) Prognosis. Brucella infection and undulant fever in man. Oxford \& New York: Oxford University Press 151-155.

39. Zinsstag J, Schelling E, Solera J, Blasco JM, Moriyo'n I (2011) Brucellosis In: Palmer SR, Soulsby L, Torgeson PR, Brown DG, editors. Handbook of Zoonoses. Oxford \& New York: Oxford University Press 54-62.

40. Mantur BG, Biradar MS, Bidri RC, Mulimani MS, Veerappa, et al. (2006) Protean clinical manifestations and diagnostic challenges of human brucellosis in adults: 16 years' experience in an endemic area. Journal of Medical Microbiology 55: 897-903.

41. Bingol A, Togay IC (2006) Neurobrucellosis as an exceptional cause of transient ischemic attacks. European Journal of Neurology 13: $544-548$

42. Young EJ (1995) An overview of human brucellosis. Clinical Infectious Diseases 21: 283-289.

43. Hasanjani Roushanm MR, Mohrez M, Smailnejad Gangi SM, Soleimani-Amir MJ, Hajiahmadi M (2004) Epidemiological features and clinical manifestations in 469 adult patients with brucellosis in babol, northern iran. Epidemiology \& Infection 132: 1109-14.

44. Kochar DK, Kumawat BL, Agarwal N, Shubharakaran N, Aseri S, et al. (2000) Meningoencephalitis in brucellosis. Neurology India 48: 170 -3.

45. Pappas G, Akritidis N, Bosilkovski M, Tsianos E (2005) Brucellosis. The New England Journal of Medicine 352: 2325 -36.

46. Bikas C, Jelastopulu E, Leotsinidis M, Kondakis X (2003) Epidemiology of human brucellosis in a rural area of northwestern peloponnese in Greece. European Journal of Epidemiology 18: 267 -274.

47. Arlett PR (1996) A case of laboratory acquired brucellosis. British Medical Journal 313: $1130-1132$

48. Yagupsky P, Baron EJ (2005) Laboratory exposures to Brucellae and implications for bioterrorism. Emerging Infectious Disease journal 11: 1180 -1185 .

49. Malik GM (1997) A clinical study of brucellosis in the Asir region of southern Saudi Arabia. The American Journal of Tropical Medicine and Hygiene 56: 375 377

50. Pappas GP, Papadimitriou N, Akritidis L, Christou EV, Tsianos (2006) "The New Global Map of Human Brucellosis." Lancet Infectious Diseases 6: 91-99.

51. Boschiroli ML, Foulongne V, O'callaghan D (2001) Brucellosis: a worldwide zoonosis. Current Opinion in Microbiology 4: 58-64.

52. (1986) Joint FAO/WHO Expert Committee on Brucellosis. World Health Organization technical report series 740: 1-132.

53. Smits HL, Kadri SM (2005) Brucellosis in India: A deceptive infectious disease. Indian Journal of Medical Research 122: 375-384.

54. European Food Safety Authority (2013) The European Union summary report on trends and sources of zoonoses and zoonotic agents and food-borne outbreaks in 2011. European Food Safety Authority 11: 3129.

55. PAHO-WHO (2001) Zoonoses and Communicable disease common to man animals and wild life, Volume I. Bacterioses and Mycoses. In: Scientific and Technical publications No.580. Pan American Health Organization Regional office of the WHO, Washington DC USA 44-67.

56. Al Dahouk S, Neubauer H, Hensel A, Schöneberg I, Nöckler K, et al. (2007) Changing epidemiology of human brucellosis, Germany, 1962-2005. Emerging Infectious Diseases 13: 1895-900.

57. Kumar R, Prabhakar RK (2013) Opportunities and challenges in Indian dairy industry supply chain: A literature review. International Journal of Logistics \& Supply Chain Management Perspectives 2: 791-800. 
58. (2007) Livestock Census. Department of Animal Husbandry, Dairying and Fisheries, Ministry of Agriculture, Government of India.

59. Government of India (2012) Basic Animal Husbandry Statistics. Department of Animal Husbandry, Dairying and Fisheries.

60. Singh G, Sharma DR, Sandhu KS, Dhand NK (2002) Economic losses occurring due to bovine abortions in Punjab. In: 10th International Congress of Asian- Australasian Association of Animal Production Societies, New Delhi, India 23-27.

61. McDermott J, Grace D, Zinsstag J (2013) Economics of brucellosis impact and control in low-income countries. Revue scientifique et technique (International Office of Epizootics) 32: 249-261.

62. Megid J, Mathias LA, Robles CA (2010) Clinical manifestations of brucellosis in domestic animals and humans. Open Veterinary Science Journal 4: 119-126.

63. Sehgal S, Bhatia R (1990) Zoonosis in India. Journal of communicable diseases 22: $227-235$

64. Renukaradhya GJ, Isloor S, Rajasekhar M (2002) Epidemiology, zoonotic aspects, vaccination and control/eradication of brucellosis in India. Veterinary Microbiology 90: 183-195.

65. Isloor S, Renukaradhya GJ, Rajasekhar M (1998) A serological survey of bovine brucellosis in India. Revue scientifique et technique (International Office of Epizootics) 17: 781-785

66. Mehra KN, Dhanesar NS, Chaturvedi VK (2000) Sero-prevalence of brucellosis in bovine in Madhya Pradesh. Indian Veterinary Journal 77: 571-573.

67. Chakraborty M, Patgiri GP, Barman NN (2000) Application on delayed-type hypersensitivity test (DTH) for the diagnosis of bovine brucellosis. Indian Veterinary Journal 77: 849-851.

68. Mathur TN (1964) Brucella strains isolated from cows, buffaloes, goat, sheep and human beings at karnal: their significance with regards to the epidemiology of brucellosis. Indian Journal of Medical Research 52: 1231- 1240.

69. Randhawa AS, Karla DS, Kapur MP (1974) Some seroepidemiologic observation on brucellosis in human and animals. Indian Journal of Medical Sciences 28: 133-8.

70. Panjarathinam R, Jhala CL (1986) Brucellosis in Gujarat state. Indian Journal of Pathology and Microbiology 29: 53-60.

71. Chauhan RS (1999) Brucellosis in India and its impact on export of buffalo Meat. Indian Journal of Animal Production 31: 16-17.

72. Hemashettar BM, Patil CS (1991) Brucellosis among practicing veterinarians. Indian Journal of Medical Microbiology 9: 45-47.

73. Mantur BG, Akki AS, Mangalgi SS, Patil SV, Gobbur RH, et al. (2004) Childhood brucellosis-a microbiological, epidemiological and clinical study. Journal of Tropical Pediatrics 50: 153 -157.

74. Handa R, Singh S, Singh N, Wali JP (1998) Brucellosis in north India: results of a prospective study. Journal of Communicable Diseases 30: 85-87.

75. Kalasinsky KS, Hadfield T, Shea AA, Kalasinsky VF, Nelson MP, et al. (2007) "Raman chemical imaging spectroscopy reagent less detection and identification of pathogens: signature development and evaluation." Journal of Analytical Chemistry 79: 2658- 2673.

76. Detilleux PG, Billy LD, Norman FC (1990)“Penetration and intracellular growth of Brucella abortus in non phagocytic cells in vitro." Infection and Immunity 58: 2320-2328.

77. Zhan Y, Kelso A, Cheers C (1995) Differential activation of Brucella reactive CD4+T cells by Brucella infection or immunization with antigenic extracts. Infection and Immunity 63: 969-975

78. Canning PC, Roth JA, Deyoe BL (1986) Release of 5'-guanosine monophosphate and adenine by Brucella abortus and their role in the intracellular survival of the bacteria. Journal of Infectious Diseases 154: 464-470.

79. Jubier-Maurin V, Boigegrain RA, Cloeckert A, Gross A, Alvares-Martinez MT, et al. (2001) Major outer membrane protein Omp 25 of Brucella suis is involved in inhibition of tumor necrosis factor alpha production during infection of human macrophages. Infection and Immunity 69: 4823-4830.

80. Yagupsky P (1999) Detection of Brucellae in blood cultures. Journal of Clinical Microbiology 37: 3437- 3442

81. Al Dahouk S, Tomaso H, Nockler K, Neubauer H, Frangoulidis D (2003)
Laboratory-based diagnosis of brucellosis-a review of the literature. Part I: Techniques for direct detection and identification of Brucella spp. Clinical Laboratory 49: 487-505.

82. Morgan WJ, MacKinnon DJ, Cullen GA (1969) The Rose Bengal plate agglutination test in the diagnosis of brucellosis. Veterinary Record 85: 636s641.

83. Nicoletti $P$ (1969) Further evaluations of serologic test procedures used to diagnose brucellosis. American Journal of Veterinary Research 30: 1811-1816.

84. Angus RD, Barton CE (1984) The production and evaluation of a buffered plate antigen for use in a presumptive test for brucellosis. In: Third International symposium on brucellosis, Algiers, Algeria, 1983. Developments in biological standardization, Basel.

85. Gall D, Nielsen K (2004) Serological diagnosis of bovine brucellosis: a review of test performance and cost comparison. Revue scientifique et technique (International Office of Epizootics) 23: 989-1002.

86. Corbel MJ (1972) Characterization of antibodies active in the Rose Bengal plate test for bovine brucellosis. Veterinary Record 90: 484-5.

87. Nielsen K, Heck F, Wagner G, Stiller J, Rosenbaum B, et al. (1984) Comparative assessment of antibody isotypes to Brucella abortus by primary and secondary binding assays. Preventive Veterinary Medicine 2: 197-204.

88. Rice C, Boyes B (1971) Serum immunoglobulins in bovine brucellosis. New Zealand Veterinary Journal 19: 146-54.

89. Barbuddhe SB, Yadava VK, Singh DK (1994) Detection of IgM and IgG antibodies against Brucella by dot-ELISA in humans. Journal of Communicable Diseases 26: 1-5.

90. Singh SV, Agrawal GS, Batra HV, Gupta VK, Singh N (2000) Monitoring of Brucella infection associated with reproductive losses using multiple serological tests in organized goat and sheep flocks. The Indian journal of animal sciences 70: $154-156$

91. Yasmin B, Selvam DT (2015). Comparative Evaluation of Native Antigens fo the Development of Brucellosis Antibody Detection System. Recent Advances in Biology and Medicine, 1: 41-50.

92. Shome R, Filia G, Padmashree BS, Krithiga N, Sahay S, et al. (2015) Evaluation of lateral flow assay as a field test for investigation of brucellosis outbreak in an organised buffalo farm: A pilot study. Veterinary World 8: 492-496.

93. Gurturk K, Bovnukara B, LIhan Z, Hakki El, Gulhan T (1999) Comparison of the dot immunobinding assay with the serum agglutination test, the rose bengal plate test and the milk ring test for the detection of Brucella antibodies in bovine sera and milk. Zentralblatt fur Veterinarmedizin. Reihe B. Journal of veterinary medicine Series B 46: 279-285.

94. Adone R, Ciuchini F, Pistoia C, Pasquali P (2002) Combined S99/RB51 antigen for complement fixation test for serological diagnosis of brucellosis in cattle and sheep. Journal of Applied Microbiology 93: 872-876.

95. Franco MP, Mulder M, Gilman RH, Smits HL (2007) Human brucellosis. Lancet Infectious Diseases 7: 775-786.

96. Lucero NE, Foglia L, Ayala SM, Gall D, Nielsen KH (1999) Competitive enzyme immunoassay for diagnosis of human brucellosis. Journal of Clinical Microbiology 37: 3245-3248.

97. Solera J, Martinez-Alfaro E, Espinosa A (1997) Recognition and optimum treatment of brucellosis. Drugs 53: 245-56

98. Solera J (2000) Treatment of human brucellosis. Le Journal medical libanais 48: $255-63$.

99. Solera J, Martinez-Alfaro E, Espinosa A, Castillejos ML, Geijo P, et al. (1998) Multivariate model for predicting relapses in human brucellosis. Journal of Infection 36: 85-92.

100. (1986) World Health Organization Joint FAOMHO Expert Committee on Brucellosis Sixth report. Technical Report Series 740. Geneva, Austria: WHO 1-132.

101. Spink WW (1960) Current status of therapy of brucellosis in human beings. Journal of the American Medical Association 172: 697-8.

102. Philippon AM, Plommet MG, Kazmierczak A, Marly JL, Nevot PA (1977) Rifampin in the treatment of experimental brucellosis in mice and guinea pigs. Journal of Infectious Diseases 136: 481-8.

103. Roushan MR, Gangi SM, Ahmadi SA (2004) Comparison of the efficacy of two 
months of treatment with co-trimoxazole plus doxycycline vs. co-trimoxazole plus rifampin in brucellosis. Swiss Medical Weekly 134: 564-8.

104. Solera J, Geijo P, Largo J, Rodriguez-Zapata M, Gijon J, et al. (2004) A randomized, double-blind study to assess the optimal duration of doxycycline treatment for human brucellosis. Clinical Infectious Diseases 39: 1776-82.

105. El Miedany YM, El Gaafary M, Baddour M, Ahmed I (2003) Human brucellosis: do we need to revise our therapeutic policy? Journal of Rheumatology 30: 2666-72.

106. Bayindir Y, Sonmez E, Aladag A, Buyukberber N (2003) Comparison of five antimicrobial regimens for the treatment of brucellar spondylitis: a prospective, randomized study. Journal of Chemotherapy 15: 466-71.

107. Young EJ (2003) Brucella species (Brucellosis). In: Yu VL, Weber R, Raoult D (eds) Antimicrobial, therapy and vaccines. Vol. I: Microbes. New York, USA: Apple Tree Productions LLC, 121-40. 